\title{
Coupling stiffness and strength analysis for bulb hydropower station concrete foundation and turbine brackets
}

\author{
DONG Yun-feng ${ }^{1, a}$, JI Jin-li ${ }^{1, a}$, QU Xing-tian ${ }^{2, b}$ and LI Zhi-he , c $^{3,}$ \\ ${ }^{1}$ Jilin Jianzhu University, Changchun, China \\ ${ }^{2}$ Jilin University, Changchun, China \\ ${ }^{3}$ Heerbin mechanical-electricity limited responsibility company, Harbin, China

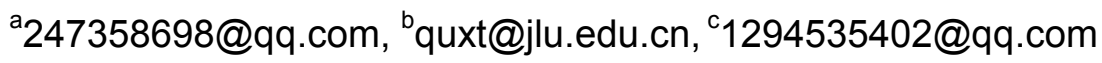

\begin{abstract}
Keywords: Concrete foundation; Turbine pipe base; Stress; Deformation
Abstract: The paper applied finite element method to analysis and calculate the stress of bulb hydropower station concrete foundation and the deformation of turbine pipe base in all load case. The analysis results indicate the main piece reciprocal infection extent and supplies the theoretical basis for safety design of the project and the equipment.
\end{abstract}

\section{Introduction}

Bulb hydropower station concrete foundation bears the effect of electromagnetic force, gravity and hydraulic conditions caused by hydro-generator and its working. Getting to hold of these applied forces are the keys to design reasonable concrete foundations. Based on the running case of the hydropower station, we analyzed a variety of operating conditions which can be seen in Table 1.

Table 1: The basic parameters of the unit

\begin{tabular}{|c|c|c|c|}
\hline basic parameter name & basic parameters & basic parameter name & basic parameters \\
\hline maximum head & $10.21 \mathrm{~m}$ & turbine bearing load & $53.5 \mathrm{t}$ \\
\hline pressure head & $15 \mathrm{~m}$ & bubble head weight & $26 \mathrm{t}$ \\
\hline rated capacity & $18000 \mathrm{kw}$ & weight of the stator & $112 t$ \\
\hline rated speed & $75 \mathrm{r} / \mathrm{min}$ & bottom ring weight & $11 \mathrm{t}$ \\
\hline thrust forward water & $297.66 \mathrm{t}$ & unilateral magnetic force & $25.8 \mathrm{t}$ \\
\hline water reverse thrust & $297.66 \mathrm{t}$ & $\begin{array}{l}\text { half of the short circuit } \\
\text { magnetic force }\end{array}$ & $250 \mathrm{t}$ \\
\hline upthrust & $314 \mathrm{t}$ & $\begin{array}{l}\text { electromagnetic torque } \\
\text { rating }\end{array}$ & $2550.6 \mathrm{kN} . \mathrm{m}$ \\
\hline generator bearing load & $102.6 \mathrm{tt}$ & & \\
\hline
\end{tabular}

\section{FEM MODEL(The finite element calculation model)}

By using ansys modeling, the shell 63 is selected as all the plate element models to analysis the turbine pipe base. The finite element calculation model is shown in Fig. 1 (a), bulb hydropower station concrete (b) the $1 / 4$ of (a) foundation based on genera [1].
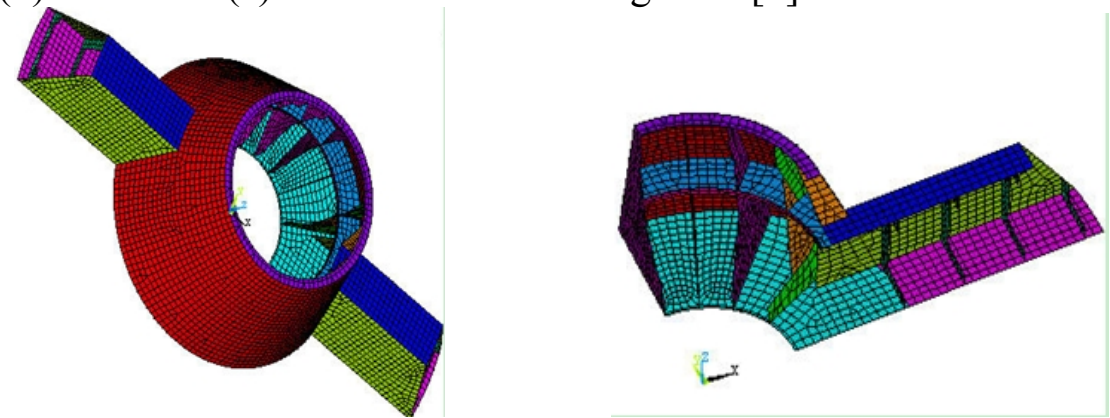

Fig. 1 Finite element calculating model 


\section{Boundary and working conditions of the loads}

The loads under various working conditions are gathered in Table. 2 [2], which can be seen as follows:

Table 2: The summary of various loads

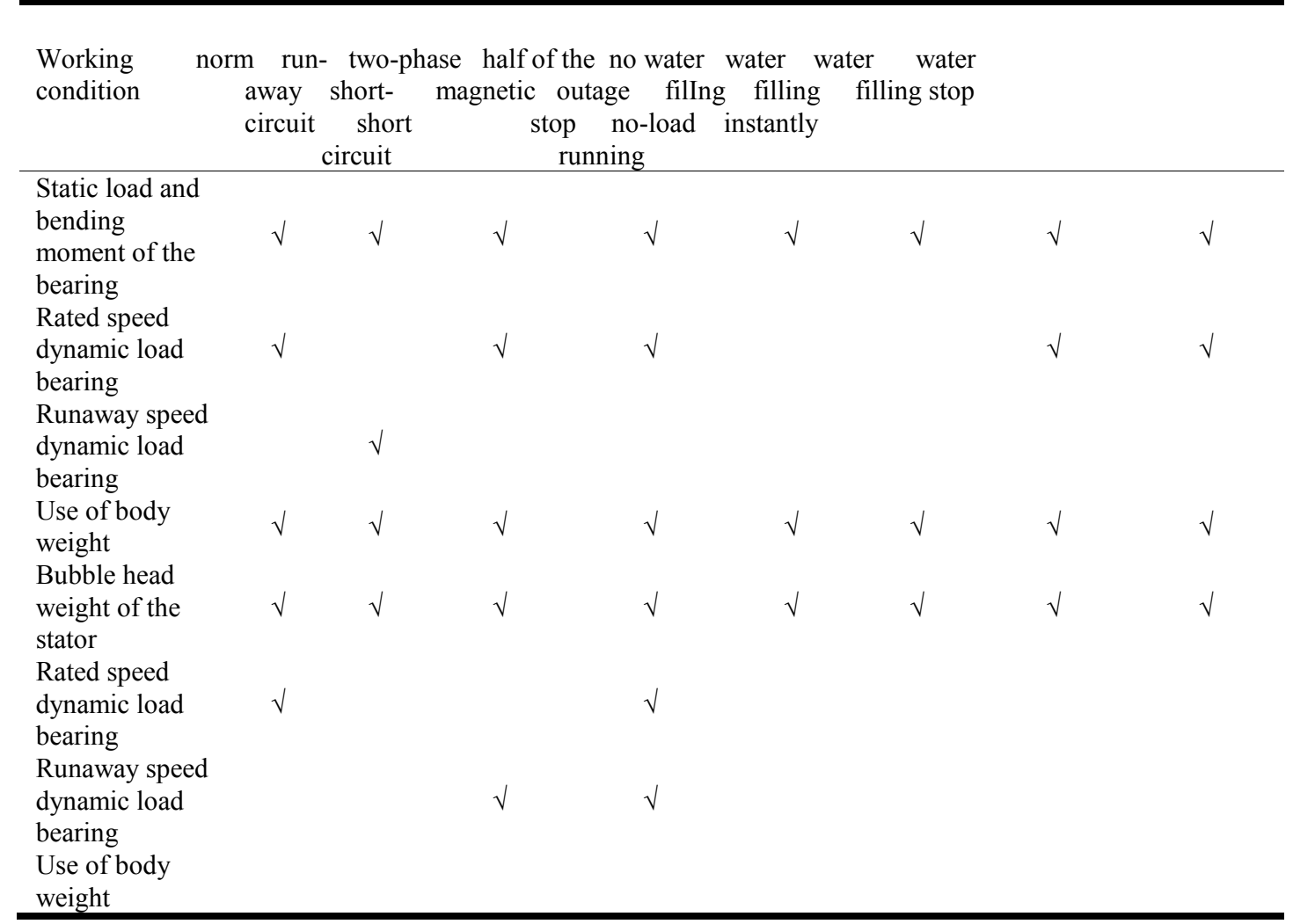

\section{The instance of calculating processes}

This section shows an instance on working condition of water filling stop instantly to analyze the experience processes, and as many as eight working conditions were considered. In order to master the extend influence of the concrete foundation, we separately analyzed two conditions on the rigidity and infinite rigidity.

3.1 The stress and strain of the calculating model without considering concrete foundation

Loading conditions (see Table 1). The stress distribution diagram is shown in Fig. 2, the maximum Von-mises stress is $242.296 \mathrm{MPa}$, and the maximum stress point of the structure is point $\mathrm{H}$. The deformation distribution is shown in Fig. 3, the maximum comprehensive deformation is $3.725 \mathrm{~mm}$, and the maximum deformation point of the structure is $\mathrm{HH}$.

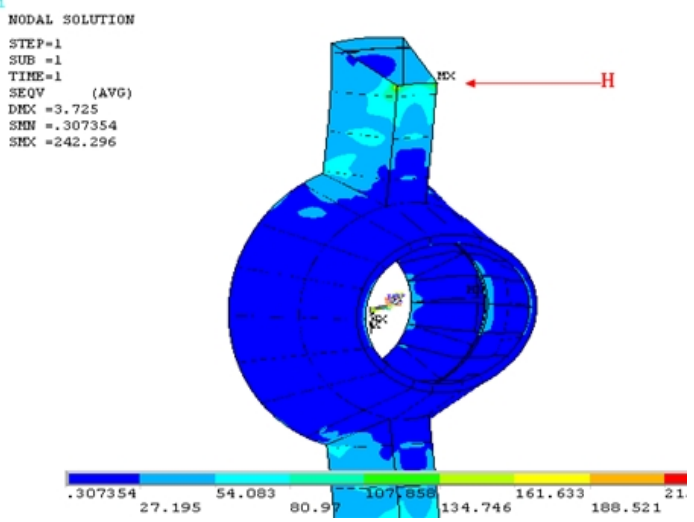

Fig.2 Stress distribution

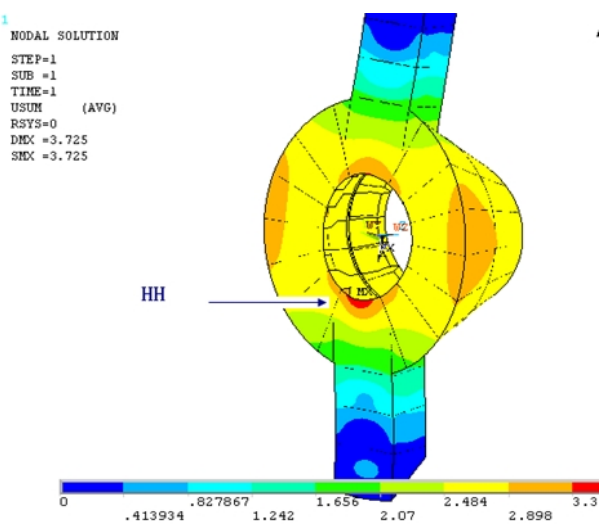

Fig. 3 Deformation distribution 
3.2 The stress and strain of the calculating model concluding concrete foundation

According to the result of section 3.1, the maximum stress appeared in the combinations between tube constellation and concrete foundation. Two reasons were used to explain the exceeded stress, one is the weaken rigidity of tube constellation, another one is the equivalent stiffness of concrete foundation boundary. This section shows the calculation results according to the concrete foundation model and accurately analyzes the combinations. Fig. 4 shows the Calculation model.

Loading conditions (see Table 2). Elastic modulus and poisson ratio of concrete foundation were given in accordance with the building code [3-4].

The stress distribution is shown in Fig. 5. The maximum Von-mises stress is 163.091MPa, and the maximum stress located in point I.

The deformation distribution is shown in Fig. 6. The maximum comprehensive deformation is $4.915 \mathrm{~mm}$, and the maximum deformation located in point II.

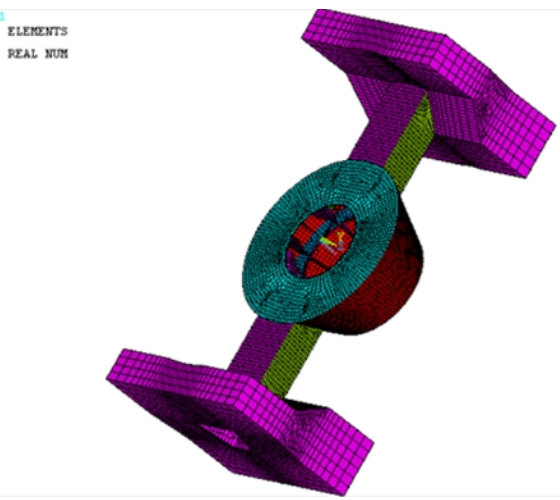

Fig.4 Calculation model

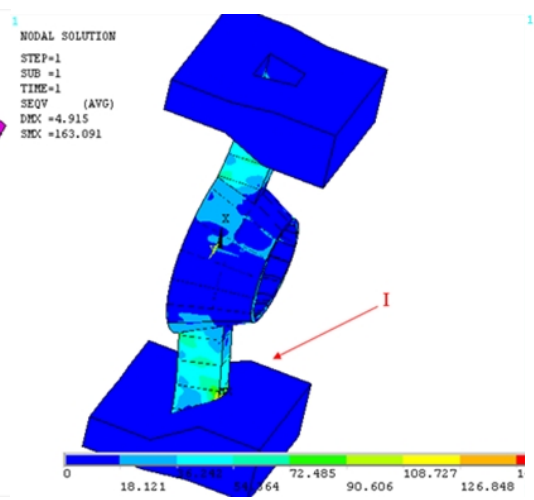

Fig. 5 Stress distribution

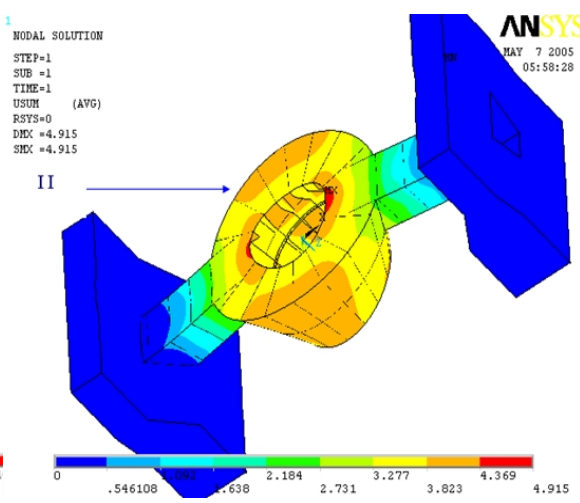

Fig.6 Deformation distribution

\section{The calculation results}

The calculation results of the maximum stress, safety factors and the position summary under various working conditions are listed in Table 3.

Table 3: The calculation results of the maximum stress under various conditions

\begin{tabular}{|c|c|c|c|c|c|c|}
\hline $\begin{array}{l}\text { working } \\
\text { condition }\end{array}$ & $\begin{array}{l}\text { the name of } \\
\text { working }\end{array}$ & $\begin{array}{l}\text { maximum stress } \\
(\mathrm{MPa})\end{array}$ & $\begin{array}{l}\text { safety factor criter } \\
\text { asses-sment to } \\
\text { sment }\end{array}$ & $\begin{array}{c}\text {-ia of acco } \\
\text { the fatigue } \\
\text { condition }\end{array}$ & $\begin{array}{l}\text { ling qualified } \\
\text { or not } \\
\text { life asses- }\end{array}$ & \\
\hline 1 & rated & 81.456 & 2.88 & $\leq 0.67 \sigma_{s}$ & -------- & qualified \\
\hline 2 & feather & 78.658 & 2.99 & $\leq \sigma_{s}$ & -------- & qualified \\
\hline 3 & $\begin{array}{l}\text { two-phase short- } \\
\text { circuit }\end{array}$ & 91.601 & 2.57 & $\begin{array}{l}\text { fatigue } \\
\text { life }\end{array}$ & $\begin{array}{c}\text { fatigue } \\
\text { life }\end{array}$ & qualified \\
\hline 4 & $\begin{array}{l}\text { Half of the } \\
\text { magnetic } \\
\text { short } \\
\text { circuit }\end{array}$ & $>235$ & ----- & $\begin{array}{l}\text { fatigue } \\
\text { life }\end{array}$ & $\begin{array}{l}\text { more } \\
\text { than } 40 \\
\text { years }\end{array}$ & qualified \\
\hline 5 & $\begin{array}{l}\text { No water } \\
\text { outage }\end{array}$ & 33.889 & 6.93 & $\leq 0.67 \sigma_{s}$ & -------- & qualified \\
\hline 6 & $\begin{array}{l}\text { Water } \\
\text { filling stop } \\
\text { Water }\end{array}$ & 94.148 & 2.50 & $\leq 0.67 \sigma_{s}$ & -------- & qualified \\
\hline 7 & $\begin{array}{l}\text { filling no-load } \\
\text { running }\end{array}$ & 75.945 & 3.09 & $\leq 0.67 \sigma_{s}$ & -------- & qualified \\
\hline 8 & $\begin{array}{c}\text { Water } \\
\text { filling } \\
\text { stop instantly }\end{array}$ & 163.091 & 1.44 & $\leq \sigma_{s}$ & -------- & qualified \\
\hline
\end{tabular}

The calculation results of the maximum deformation and the position summary under various working conditions are listed in Table 4. 
Table 4 The calculation results of the maximum deformation under various conditions

\begin{tabular}{ccc}
$\begin{array}{c}\text { working } \\
\text { conditio } \\
\mathrm{n}\end{array}$ & name of working condition & $\begin{array}{c}\text { maximum deformation } \\
(\mathrm{mm})\end{array}$ \\
\hline 1 & rated & 1.344 \\
2 & feather & 1.346 \\
3 & two-phase short-circuit & 1.388 \\
4 & half of the magnetic short circuit & 10.487 \\
5 & no water outage & 0.45 \\
6 & Water filling stop & 1.177 \\
7 & water filling no-load running & 0.882 \\
8 & water filling stop instantly & 4.915 \\
\hline
\end{tabular}

The calculation results of the maximum deformation under directions of the rated conditions and the location are listed in Table 5.

Table 5 The calculation results of the maximum deformation under the rated conditions

\begin{tabular}{ccc}
\hline computational condition & direction & $\begin{array}{c}\text { maximum deformation } \\
(\mathrm{mm})\end{array}$ \\
\hline The magnetic force and & opposite direction with gravity & 0.34 \\
buoyancy in the same direction & direction perpendicular with gravity & 0.41 \\
The magnetic force and & Axis direction & 1.354 \\
buoyancy in the direction & opposite direction with gravity & 0.34 \\
perpendicular & direction perpendicular with gravity & 0.46 \\
\hline
\end{tabular}

\section{Conclusions}

On the normal operation condition, the maximum comprehensive stress of the tube is less than two-thirds of the material yield limit, which meets the safety standard requirements. Under the working condition that the runaway stops and water is filling, the maximum comprehensive stress of the tube type is less than the material yield limit, which meets the safety standard requirements. At the same time, on the condition of two phase short circuit and magnetic short circuit of half the cases, the tube allows the impact of more than 40 times in the number. According to the annual inspection, the tube is provided to safely run more than 40 years. Due to the maximum comprehensive stress appears in the junction of concrete and tube type water filling stop instantly, the stiffness rigid of the concrete foundation is an important factor which should be considered into the calculation.

\section{References}

[1] Molin Wan, Jiyun Han. Technology for reinforcement of concrete[M]. Chinese Building Industry Press, 1995. (in Chinese)

[2] Tao Wang, Enhua Zhou, Huanchun Zhu, et al. Deformation analysis of middle pier in three gorges permanent shiplock[J]. Rock and Soil Mechanics, 2002, 23(6): 683-686. (in Chinese)

[3] Technical specification for reinforced concrete structure(CECS25:90). China Planning Press, 19 92. (in Chinese)

[4] Code for design of concrete structure(GB50010-2002). 